\title{
Potential of magnetic nanoparticles for targeted drug delivery
}

This article was published in the following Dove Press journal:

Nanotechnology, Science and Applications

24 August 2012

Number of times this article has been viewed

\author{
Hung-Wei Yang ${ }^{1,2}$ \\ Mu-Yi Hua' \\ Hao-Li Liu ${ }^{3}$ \\ Chiung-Yin Huang ${ }^{2}$ \\ Kuo-Chen Wei ${ }^{2}$
}

'Molecular Medicine Research Center, Department of Chemical and Materials Engineering, Chang Gung University, ${ }^{2}$ Department of Neurosurgery, Chang Gung University and Memorial Hospital, ${ }^{3}$ Department of Electrical Engineering, Chang Gung University, Taoyuan, Taiwan
Correspondence: Kuo-Chen Wei Department of Neurosurgery, Chang Gung University and Memorial Hospital, 5 Fu-Hsing Road,

Kuei-Shan, Taoyuan 33305, Taiwan

Tel +886 $3328 \quad 1200$ ext 2412

Fax +886 33285818

Email kuochenwei@cgmh.org.tw
Abstract: Nanoparticles (NPs) play an important role in the molecular diagnosis, treatment, and monitoring of therapeutic outcomes in various diseases. Their nanoscale size, large surface area, unique capabilities, and negligible side effects make NPs highly effective for biomedical applications such as cancer therapy, thrombolysis, and molecular imaging. In particular, nontoxic superparamagnetic magnetic NPs (MNPs) with functionalized surface coatings can conjugate chemotherapeutic drugs or be used to target ligands/proteins, making them useful for drug delivery, targeted therapy, magnetic resonance imaging, transfection, and cell/protein/ DNA separation. To optimize the therapeutic efficacy of MNPs for a specific application, three issues must be addressed. First, the efficacy of magnetic targeting/guidance is dependent on particle magnetization, which can be controlled by adjusting the reaction conditions during synthesis. Second, the tendency of MNPs to aggregate limits their therapeutic use in vivo; surface modifications to produce high positive or negative charges can reduce this tendency. Finally, the surface of MNPs can be coated with drugs which can be rapidly released after injection, resulting in targeting of low doses of the drug. Drugs therefore need to be conjugated to MNPs such that their release is delayed and their thermal stability enhanced. This chapter describes the creation of nanocarriers with a high drug-loading capacity comprised of a high-magnetization MNP core and a shell of aqueous, stable, conducting polyaniline derivatives and their applications in cancer therapy. It further summarizes some newly developed methods to synthesize and modify the surfaces of MNPs and their biomedical applications.

Keywords: magnetic nanoparticles, drug delivery, biomedical applications, cancer therapy

\section{Introduction}

Nanotechnology has been successfully applied for disease diagnosis, in vivo molecular imaging, and as an improved therapeutic platform. Nanoparticles (NPs) are particularly advantageous due to their small size, large surface area, in vivo drug delivery characteristics, ${ }^{1}$ and unusual electronic, ${ }^{2}$ optical, ${ }^{3}$ and magnetic ${ }^{4}$ properties. With the recent development of nanobiotechnology, magnetic NPs (MNPs) have gained increasing attention for use in biomedical applications such as magnetic resonance imaging (MRI), ${ }^{5}$ virus detection, ${ }^{6}$ magnetic cell separation, ${ }^{7}$ enzyme catalysis, ${ }^{8}$ gene therapy,${ }^{9}$ targeting chemotherapy, ${ }^{10}$ and radiotherapy. ${ }^{11}$ A major problem in cancer therapy is the lack of specificity of chemotherapeutic drugs towards the tumor site. Large doses of drugs with serious side effects thus need to be injected to achieve efficient local concentrations at the tumor. Current efforts are focused on developing strategies for targeted drug delivery including both molecular and magnetic targeting systems. Given the limited knowledge of suitable biomarkers for efficient molecular targeting, cooperative 
targeting by a combination of molecular biomarkers with superparamagnetic MNP carriers is a particularly promising strategy for cancer therapy.

Magnetic nanocarriers need to be stable in water at neutral $\mathrm{pH}$ and normal saline for biological, medical diagnostic, and therapeutic applications. Iron oxide MNPs are widely used as the core of magnetic nanocarriers. However, the surface of MNPs need to be coated to prevent the formation of large aggregates and provide functional groups (amines or carboxylic acid) for bioconjugation to anticancer drugs and/or targeted ligands. Various surface coatings have been used, including lipids, ${ }^{12,13}$ liposomes, ${ }^{14,15}$ proteins, ${ }^{16-18}$ polymers, ${ }^{19-22}$ and dextran. ${ }^{23}$ MNPs are also commonly used as an MRI T2 contrast agent for contrast enhancement and signal amplification since they are much more efficient promoters of relaxation than the MRI T1 contrast agent gadolinium-diethylenetriaminepentaacetic acid, and their magnetic properties can be managed by controlling their size and surface coatings. ${ }^{24}$ The most important consideration for clinical application of MNPs is their nontoxicity. MNPs based on magnetite $\left(\mathrm{Fe}_{3} \mathrm{O}_{4}\right)$ and maghemite with satisfactory biocompatibility have therefore been under intense investigation to meet criteria such as a long blood retention time, biodegradability, and low toxicity. ${ }^{25,26}$

This review will focus on recent advances in the development of an integrated system of magnetic nanocarriers, their conjugation chemistry, and detection technology and will discuss their broad application in drug delivery, targeted therapy, molecular imaging, and therapeutic decision-making and monitoring for gliomas (malignant brain tumors), prostate cancer, and bladder cancer.

\section{Surface modification of MNPs}

Among the many different kinds of chemical methods for synthesizing MNPs, a precipitation-based approach is most commonly used. ${ }^{27}$ Different sizes of MNPs including small MNPs (60-150 nm) and ultra small MNPs (10-50 nm) can affect their magnetic properties and affect their functions in various applications. ${ }^{28,29}$ Uncoated MNPs are unstable in aqueous media and readily aggregate and precipitate. The surfaces of MNPs are therefore coated with a variety of different molecules to eliminate or minimize their aggregation under physiological conditions. ${ }^{30}$ Since the surfaces of target cells are negatively charged, most MNPs are modified with cationic materials that contain functional groups to conjugate biological molecules and drugs. The most common coatings are dextran or polyethylene glycol (PEG) derivatives, polyethylene oxide, poloxamers, and polyoxamines to minimize or eliminate opsonization of MNPs. ${ }^{31}$ Adsorption of the protein on the hydrophobic surface of NPs makes the surface hydrophilic after injection of NPs in the bloodstream. Recognition of coated NPs by macrophages of the reticuloendothelial system is driven by the adsorbed protein chemistry or immunology. ${ }^{32}$ Detection by the reticuloendothelial system can be avoided by using MNPs coated with either protein-resistant PEGylated derivatives or hydrophilic polymers, which prevent binding of circulatory proteins and slow the clearance process. ${ }^{33}$ Surface coating is also critical to allow conjugation of a variety of biological molecules or drugs. Polypeptides, poly(L-glutamate), ${ }^{34}$ poly (D,Llactide), hyaluronic acid layers, ${ }^{35}$ and carboxyl-functionalized poly(amidoamine) dendrimers ${ }^{36}$ have proven to be the best choices for shell materials due to their low toxicity, biocompatibility, and reticuloendothelial system stability.

The authors recently developed a new class of superparamagnetic high-magnetization MNPs (HMNPs) composed of an $\mathrm{Fe}_{3} \mathrm{O}_{4}$ core and an aqueous-stable, hydrophilic, cationic poly(aniline-co-N-[1-one-butyric acid])aniline shell with biocompatible O-(2-aminoethyl)PEG (EPEG) derivatives and a uniform size distribution ranging from 15-30 nm. This poly(aniline-co-N-[1-one-butyric acid])aniline coating polymer was developed by the authors' group and has surface reactivity for introducing different or multiple functional groups including carboxylic and amine groups that can be used to conjugate anticancer drugs and tumor-targeting biomolecules such as peptides or antibodies (Figure 1). ${ }^{37-41}$ Despite significant efforts in developing MRI contrast agents and drug carriers based on MNP formulations, there are still several obstacles to be overcome. A major challenge is how to attain stability, high magnetization, and high MRI contrast to avoid decay of magnetic gradients over distance and thrombosis in blood vessels and organs. ${ }^{42,43}$

\section{Current applications of MNPs}

Magnetic carrier technology was first used in the early 1940s as a new method of wastewater treatment. ${ }^{44}$ The use of MNPs for drug delivery has been evolving since 1963 and MNPs consisting of $\mathrm{Fe}_{3} \mathrm{O}_{4}$ or maghemite cores coated with biocompatible and functional polymers have become a major research focus for targeted drug delivery. ${ }^{45}$ MNPs can be used in a wide variety of biomedical applications, ranging from contrast agents for MRI to the destruction of cancer cells via hyperthermia treatment, targeted therapy, and separation (Figure 2). Most of these promising applications require well defined and controllable interactions between the MNPs and living cells. 
<smiles>CNC(=O)N(CCCl)CCCl</smiles>

BCNU

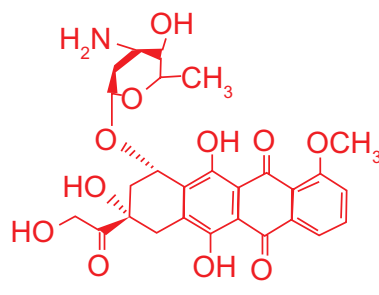

Epirubicin or doxorubicin

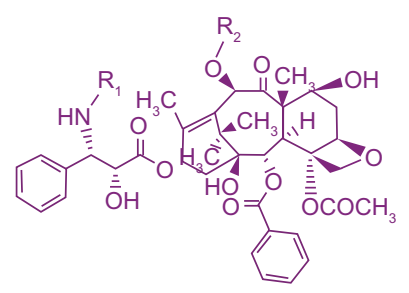

Paclitaxel<smiles>N#[13C]C(=O)c1ccccc1</smiles>

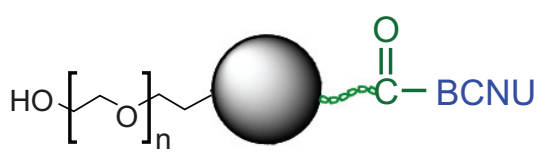

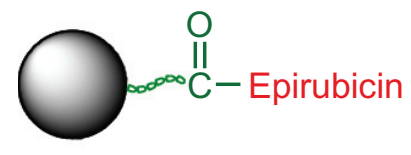

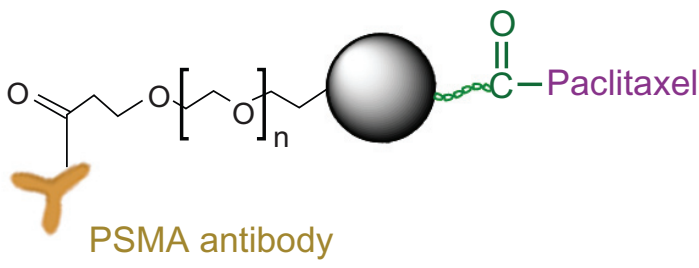

Figure I The chemical structures of magnetic nanomedicine based on magnetic nanoparticles.

Abbreviations: BCNU, bis-chloroethylnitrosourea; PSMA, prostate-specific membrane antigen.

\section{Magnetic fluid hyperthermia}

Hyperthermia is a promising approach for cancer therapy, and has been induced by a variety of methods including hot water, capacitive heating, and induction heating. ${ }^{46}$ For thermoablation, a tumor is subjected to temperatures $>46^{\circ} \mathrm{C}$ and $\leq 56^{\circ} \mathrm{C}$, causing cells to undergo direct tissue necrosis, coagulation, or carbonization. Moderate hyperthermia, traditionally termed hyperthermia treatment, has various effects both at the cellular and tissue level. Cells undergo heat stress in the temperature range of $41^{\circ} \mathrm{C}-46^{\circ} \mathrm{C}$ resulting in activation and/or initiation of many intra- and extracellular degradation

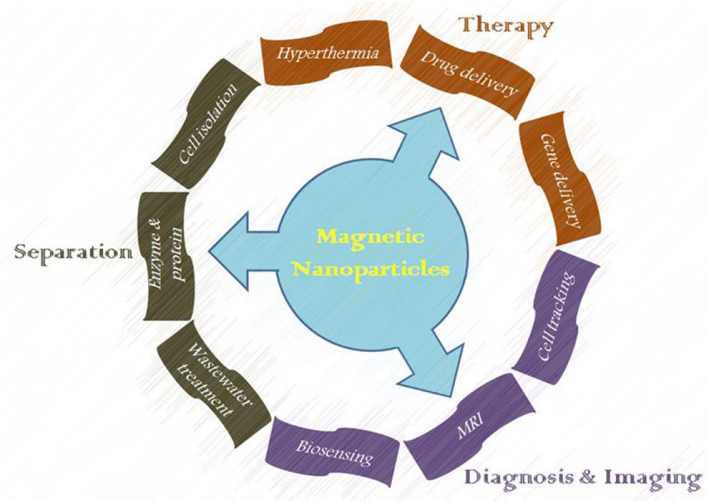

Figure 2 Biomedical applications of magnetic nanoparticles. Abbreviation: MRI, magnetic resonance imaging. mechanisms like protein denaturation, protein folding, aggregation, and DNA crosslinking. Permanent irreversible protein damage can be caused by a single heat treatment resulting in protein aggregation and/or inhibition of many cellular functions. ${ }^{47}$ Matsuoka et al developed magnetic cationic liposomes based on superparamagnetic iron oxide NPs and investigated their in vivo efficacy for hyperthermia treatment of hamster osteosarcoma. ${ }^{48}$ Magnetoliposomes were injected directly into the osteosarcoma and were then subjected to an alternating magnetic field. The tumor was heated above $42^{\circ} \mathrm{C}$, and complete regression was observed in $100 \%$ of the treated hamsters. At day twelve, the average tumor volume of the treated hamsters was about $1 / 1000$ of that of the control hamsters. Du et al assessed the thermodynamic characteristics of a nanosized arsenic trioxide $/ \mathrm{Fe}_{3} \mathrm{O}_{4}$ complex and validated the hyperthermia effect when combined with magnetic fluid hyperthermia on xenograft HeLa cells (human cervical cancer cell line) in nude mice. ${ }^{49}$ Thermochemotherapy with these MNPs showed a significant inhibitory effect on the mass ( $88 \%$ reduction) and volume (91\% reduction) of xenograft cervical tumors. These nanosystems combined with magnetic fluid hyperthermia are thus a promising technique for the minimally invasive elimination of solid tumors and may also be useful for the treatment of metastasis by inhibiting the expression of several growth-related factors. 
Jang et al showed that a dopant could be properly positioned in tetrahedral sites - substituting into the down spin site with a nonmagnetic dopant atom results in an overall increase in the moment per unit cell - and demonstrated the capability of scaling up. ${ }^{50}$ In addition, their doped MNPs showed very high saturation magnetization (175 emu/g), an eight- to fourteenfold increase in MRI contrast and a four-fold enhancement in hyperthermic effects compared to conventional MNPs.

\section{Magnetic separation}

Magnetic separation of cells has several advantages over other enrichment techniques. It permits the target cells to be isolated directly from crude samples such as blood, bone marrow, tissue homogenates, stool, cultivation media, food, water, and soil. MNPs have been developed as magnetic carriers in various separation processes including purification, immunoassays, and even separation of transiently transfected cells using antibody-linked MNPs. ${ }^{51,52}$ Immunomagnetic separation of Salmonella cells was used to avoid false negative polymerase chain reaction results caused by polymerase chain reaction inhibitors in processed food products. ${ }^{53}$ In this case, magnetic hydrophilic microspheres based on poly (2-hydroxyethyl methacrylate-co-ethylene dimethacrylate) functionalized with polyclonal Salmonella antibodies were preferable to hydrophobic MNPs.

Enzymes are versatile proteins with great potential for applications in research and industry due to their myriad of biocatalytic functions. However, their lack of long-term stability has complicated their separation and reuse, often requiring extensive downstream processing. ${ }^{54}$ Over the last decade, MNPs have been used as support materials for immobilization of enzymes such as yeast alcohol dehydrogenase $^{55}$ and lipase, ${ }^{56}$ with various surface modifications. Glucose oxidase has been immobilized on different types of solid supports using glutaraldehyde as a crosslinking agent for biosensor and biofuel cell applications. ${ }^{57,58}$ Dyal et al presented a strategy to immobilize Candida rugosa lipase on functionalized maghemite NPs. ${ }^{59}$ The hybrid lipase-NP composites showed a decrease in activity of about $15 \%$ over 1 month and had good long-term stability. Huang et al covalently bound glucose oxidase to $\mathrm{Fe}_{3} \mathrm{O}_{4}$ / silicon dioxide MNPs using glutaraldehyde, resulting in an activity of immobilized glucose oxidase of $4570 \mathrm{U} / \mathrm{g}$ at $\mathrm{pH} 7$ and $50^{\circ} \mathrm{C} .{ }^{60}$ The immobilized glucose oxidase retained $80 \%$ of its initial activity after 6 hours at $45^{\circ} \mathrm{C}$ compared to only $20 \%$ for the free enzyme. After six cycles of repeated use, the immobilized glucose oxidase still maintained $60 \%$ of its initial activity; $75 \%$ of its initial activity remained after 1 month at $4^{\circ} \mathrm{C}$ compared to $62 \%$ for the free enzyme. Different enzymes that could be associated with MNPs include glucoamylase, cytochrome c oxidase, $\beta$-lactamase, chymotrypsin, alcohol dehydrogenase, glucose oxidase, galactose oxidase, urease, neuraminidase, papain, deoxyribonuclease, and ribonuclease. The excellent properties of MNPs, especially long-term stability and easy separation, make the use of expensive enzymes economically viable and hence open a new horizon for enzyme catalysis in biotechnology.

Selective separation of DNA and ribonucleic acid is an important tool in clinical diagnostics of microorganisms and viruses, genomic profiling, and gene manipulation, and is commonly performed using functionalized MNPs. ${ }^{61}$ To separate a target nucleic acid from a mixture, MNPs are functionalized with either streptavidin or a short oligonucleotide. ${ }^{62}$ The target nucleic acid or oligonucleotide is then captured either via its modification with biotin, or by hybridization to the complementary immobilized nucleic acid or oligonucleotide. The target nucleic acid can be separated either by capturing on the solid phase or by retaining the background on the solid phase. ${ }^{63}$ This system can also be used to remove disease-causing factors from blood. Wang et al developed biofunctional MNPs decorated by bisphosphonate, which coordinates the uranyl ion with high affinity and is capable of efficient removal of radionuclides. ${ }^{64}$ These $\mathrm{Fe}_{3} \mathrm{O}_{4}$-bisphosphonate MNPs remove 99\% and $69 \%$ of the uranyl ion from water and blood, respectively. Herrmann et al developed nanomagnets (carbon-coated iron carbide) and functionalized them with ethylenediaminetetraacetic acid-like chelators, antidigoxin antibody fragments (digoxin immune antigen-binding fragment), or entire antibodies (antihuman interleukin-6). ${ }^{65}$ After magnetic extraction using metal-chelating nanomagnets, the median lead concentration was decreased by $56 \%$ down to $0.53 \mu \mathrm{g} / \mathrm{mL}$ in human whole blood (initial lead ${ }^{2+}$ concentration: $1.2 \mu \mathrm{g} / \mathrm{mL}$ ). Future research will need to focus on extending these findings to achieve continuous blood purification and extraction inside a whole organism.

\section{Tumor imaging and magnetic delivery system}

MRI is an extremely useful diagnostic tool in medical science and is the preferred method for imaging the brain and central nervous system, assessing cardiac function, and detecting tumors. Since MRI delivers anatomic images of soft tissue with high resolution, it is expected to become a very important tool for molecular and cellular imaging. ${ }^{66}$ The ability to image crosslinked iron oxide and related NPs by 
magnetic resonance has led to the development of several probes for imaging cellular and subcellular events with high spatial resolution, ${ }^{67-70}$ which can be used for early diagnosis, risk stratification, and monitoring of disease activity or therapeutic efficacy. For example, a magnetofluorescent NP targeted to vascular adhesion molecule-1 (VCAM-1) was designed to image atherosclerosis in vivo. Upregulation of VCAM-1 on activated endothelial cells, macrophages, and smooth muscle cells is an early marker of atherosclerosis. A VCAM-1 targeting peptide was selected by iterative phage display and conjugated to crosslinked iron oxide. Intravenous administration of this targeted particle resulted in an enhanced MRI signal in aortic roots of mice, which correlated with VCAM-1 expression. This probe was also useful for in vivo monitoring of therapeutic efficacy, as evidenced by improved signal after statin treatment.

Iron oxide NPs have also been successfully used to diagnose cancer in vivo without any targeting ligands on their surface, termed passive targeting. ${ }^{71}$ For more efficient targeted imaging, the surfaces of the MNPs need to be conjugated with active targeting probes, such as antibodies and proteins. The specific interactions between targeting agents and receptors allow accumulation of these nanostructures near the desired tissue.

Magnetofection is a new method to enhance the introduction of gene vectors into cells. ${ }^{72}$ The idea is to associate MNPs with DNA together with either a transfection reagent or a viral vector. This technology allows delivery of the genetic material to the target cell surface. DNA is then released into the cytoplasm, with the hope that the MNPs will not influence cellular function. Magnetofection has also been successfully used to deliver antisense oligonucleotides in vitro and in vivo. ${ }^{73}$ Hirao et al and Zheng et al developed magnetic cationic liposomes by incorporating MNPs into small cationic liposomes. ${ }^{74,75}$ A gene delivery system combining these magnetic cationic liposomes and magnetic induction was found to enhance transfection efficiency in human osteosarcoma cells.

\section{Rationale of using MNPs in drug delivery}

Basic concepts of MNPs for biological use MNPs are also known as superparamagnetic iron oxide particles and have been used as contrast agents for MRI for more than 20 years. At the same time, therapeutic applications of MNPs have rapidly expanded. Magnetic targeting is a promising strategy for achieving localized drug delivery to tumor tissue. The deposition, accumulation, and retention of drug-conjugated MNPs in tumors are enhanced by magnetic force. The feasibility of this application has recently been demonstrated in brain tumors. ${ }^{76,77}$ Chertok et al showed that accumulation of NPs was consistently enhanced with 9.6-fold selectivity for MNP accumulation in gliomas compared to the contralateral brain site. ${ }^{76}$ The MNP distribution can be monitored in vivo by MRI in the brain. For example, MR spin-spin (R2) relaxivity measurements have been used to compare the $\mathrm{R} 2$ maps of animals that received intravenously administered MNPs with and without 0.4-T magnetic targeting. The distribution of MNPs could be visualized in vivo in the brain and magnetic targeting induced a five- to tenfold increase in MNP accumulation in the total tumor mass.

\section{Applications of MNPs in site-specific targeting}

Site-specific drug delivery to brain tumors

Traditional chemotherapeutic agents can be conjugated to HMNPs to form therapeutic HMNPs, for example HMNP-bis-chloroethylnitrosourea (BCNU), HMNPepirubicin, HMNP-doxorubicin, or HMNP-paclitaxel (Figure 2). The chemotherapeutic agent BCNU (also known as carmustine) has been commercialized for the treatment of gliomas, but its efficacy is limited by a short half-life in the human body. BCNU was therefore immobilized on HMNPs to reduce its hydrolysis rate and prolong its half-life. The concentrations of therapeutic MNPs that were required for $50 \%$ inhibition of cellular growth $\left(\mathrm{IC}_{50}\right.$ ) of glioma cells (C6, U87) were initially determined in vitro. Pure HMNPs without conjugated anticancer drugs have no apparent cytotoxic effect when cocultured in vitro with tumor cells. In contrast, abundant HMNP-BCNU or HMNP-epirubicin that was presumably taken up by endocytosis could be observed within cells by transmission electron microscopy. These particles entered the nuclei and appeared to induce apoptosis. Liu et al demonstrated that the $\mathrm{IC}_{50}$ of free epirubicin and HMNP-epirubicin was $6.7 \mu \mathrm{g} / \mathrm{mL}$ and $5.2 \mu \mathrm{g} / \mathrm{mL}$ for C6 cells, respectively. ${ }^{78}$ The value was significantly reduced to $1.6 \mu \mathrm{g} / \mathrm{mL}$ by magnetic targeting (Figure $3 \mathrm{~A}$ ). ${ }^{78} \mathrm{Hua}$ et al also demonstrated that free BCNU and HMNP-BCNU were also both toxic to $\mathrm{C} 6$ cells in a dose-dependent manner. ${ }^{38}$ The $\mathrm{IC}_{50}$ of HMNP-BCNU was $6.9 \mu \mathrm{g} / \mathrm{mL}$, which was lower than that of free BCNU $(8.6 \mu \mathrm{g} / \mathrm{mL})$ due to greater thermal stability and a decreased rate of hydrolysis of conjugated $\mathrm{BCNU}$, all leading to more efficient delivery of BCNU into cells at $37^{\circ} \mathrm{C}$. Magnetic targeting of HMNP-BCNU led to a significant reduction in the $\mathrm{IC}_{50}$ to only $4.3 \mu \mathrm{g} / \mathrm{mL}$, suggesting that more HMNP-BCNU was effectively guided to 
A

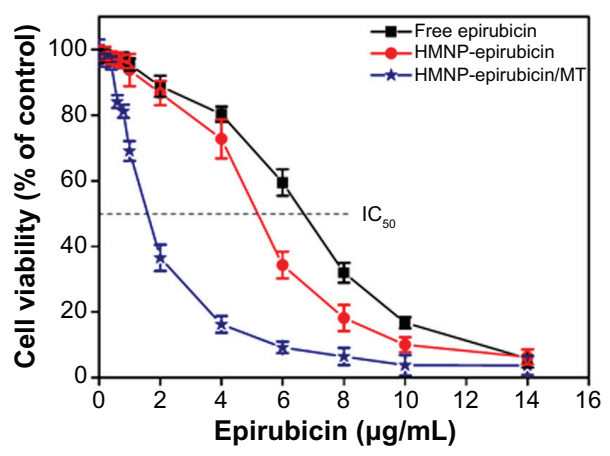

C

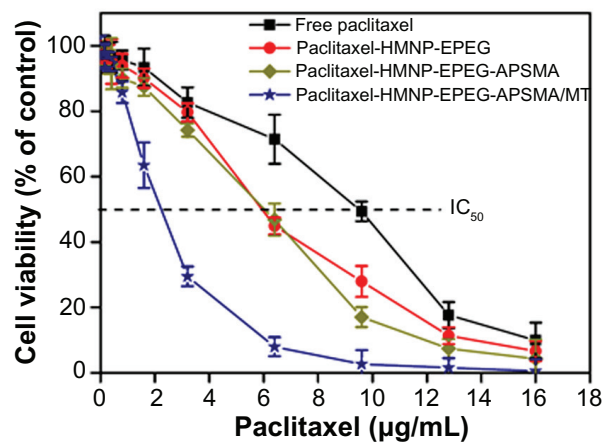

B

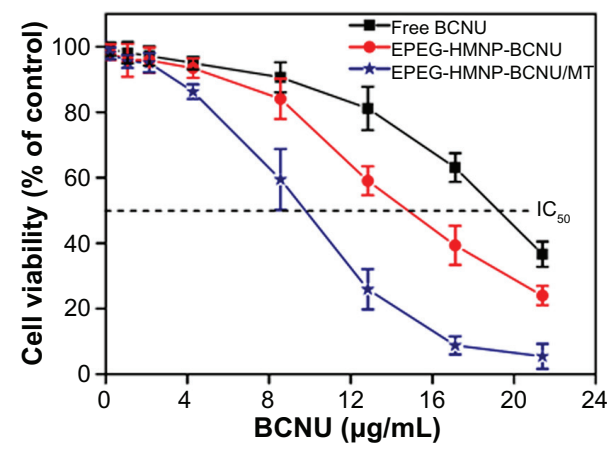

D

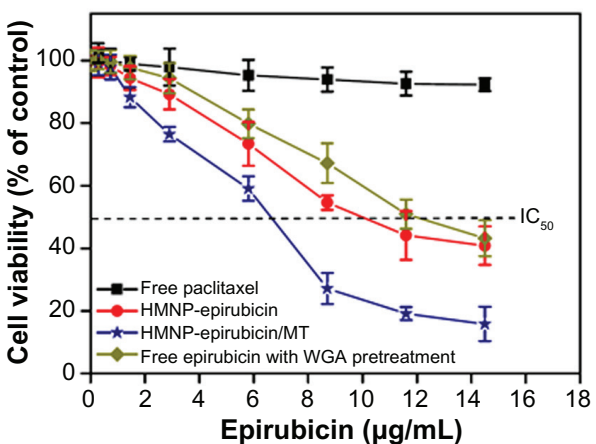

Figure 3 (A) Viability of glioma C6 cells after treatment with high-magnetization magnetic nanoparticle-epirubicin. (B) Viability of glioma U87 cells after treatment with O-(2-aminoethyl)polyethylene glycol-high-magnetization magnetic nanoparticle-bis-chloroethylnitrosourea. (C) Viability of prostate cancer CWR22R cells after treatment with paclitaxel conjugates. (D) Viability of bladder tumor MGH-UIR cells after treatment with high-magnetization magnetic nanoparticle-epirubicin.

Note: Values represent mean \pm standard deviation $(\mathrm{n}=8)$.

Abbreviations: BCNU, bis-chloroethylnitrosourea; EPEG, O-(2-aminoethyl)polyethylene glycol; HMNP, high-magnetization magnetic nanoparticle; IC ${ }_{50}$, half maximal inhibitory concentration; MT, magnetic targeting; WGA, wheat germ agglutinin.

and concentrated at the target area. To provide more effective HMNPs, Yang et al developed a self-protecting high-magnetic nanomedicine (EPEG-HMNP-BCNU) which was designed by grafting a biocompatible polymer (EPEG) onto the surface of HMNP-BCNU (Figure 2).$^{39}$ EPEG protects $\mathrm{BCNU}$ by slowing down its rate of hydrolysis and prolonging the circulation time of MNPs. The half-life of BCNU was prolonged from 30 hours (HMNP-BCNU) to 62 hours. Free BCNU and EPEG-HMNP-BCNU were both toxic to U87 cells in a concentration-dependent manner. However, the $\mathrm{IC}_{50}$ of EPEG-HMNP-BCNU was $14.7 \mu \mathrm{g} / \mathrm{mL}$, which was lower than that of free BCNU $(19.2 \mu \mathrm{g} / \mathrm{mL})$. Moreover, the value was reduced significantly to only $9.8 \mu \mathrm{g} / \mathrm{mL}$ when an external magnetic field of 800 gauss was applied to the EPEG-HMNP-BCNU particles (Figure 3B). ${ }^{39}$ Hua et al successfully used magnetic targeting to deliver HMNP-BCNU into brain tumor implant animal cells. ${ }^{38}$ Tumors shrank markedly after 7 days of treatment with $5 \mu \mathrm{g} / \mathrm{kg}$ of HMNP-BCNU and 24 hours of magnetic targeting. In contrast, tumor growth was not inhibited after 7 days by $13.5 \mathrm{mg} / \mathrm{kg}$ free BCNU or $1.68 \mathrm{mg} / \mathrm{kg}$ HMNP-BCNU with magnetic targeting.

Significant accumulation of MNPs in the brain relies on a temporary opening of the blood-brain barrier. Liu et al first demonstrated the application of focused ultrasound (FUS) blood-brain barrier disruption to enhance MNP delivery into the brain in small animals. ${ }^{79}$ Their aim was to deliver MNPs into the brain and to then monitor these MNPs by MRI to simultaneously detect blood-brain barrier disruption and follow the status change of sonicated brain over time. They used an MNP contrast agent that was clinically approved for blood pool MRI (carboxydextran-coated, 60-nm hydrodynamic size, Resovist ${ }^{\mathbb{}}$; Bayer AG, Leverkusen, Germany). The local distribution of MNPs in the brain causes field inhomogeneity and concomitant signal loss on T2*-weighted images. The $\mathrm{T} 2 *$-weighted images obtained before and after MNP administration and FUS delivery could therefore be used to detect the blood-brain barrier disruption effect. The biodistribution of MNPs in the brain could also be followed over time by collection of $\mathrm{T} 2 *$-weighted images. Over $70 \%$ of MNPs were cleared from the brain within 7 days.

A significant increase in therapeutic HMNP deposition has also been demonstrated using this method in tumorbearing animals. ${ }^{78}$ Untreated animals showed no HMNP accumulation after HMNP-epirubicin administration. However, 11,982 \pm 2105 ng HMNP-epirubicin was delivered when it was administered in combination with FUS/magnetic 
targeting, providing a 15-fold higher concentration than the therapeutic range in breast cancer $(819 \pm 482 \mathrm{ng} / \mathrm{g}$ tumor) that had previously been reported for doxorubicin to reach a clinical response rate of 39\% (Figure 4A). Control of tumor progression and survival were also investigated at 7 -day intervals. The tumor volume in the FUS/magnetic targeting group only increased by $106 \% \pm 24 \%$ in treated animals compared with a $533 \% \pm 123 \%$ increase in controls and $406 \% \pm 78 \%$ increase in free epirubicin-treated group, indicating that the combination of therapeutic HMNPs with FUS/magnetic targeting provided the most effective means of controlling tumor progression (Figure 4B). Moreover, the control and FUS enhancement-only treatment resulted in similar median animal survival times (23 days and 20 days, respectively), whereas the median survival times were significantly improved by $66 \%$ in animals receiving HMNPepirubicin in conjunction with FUS/magnetic targeting

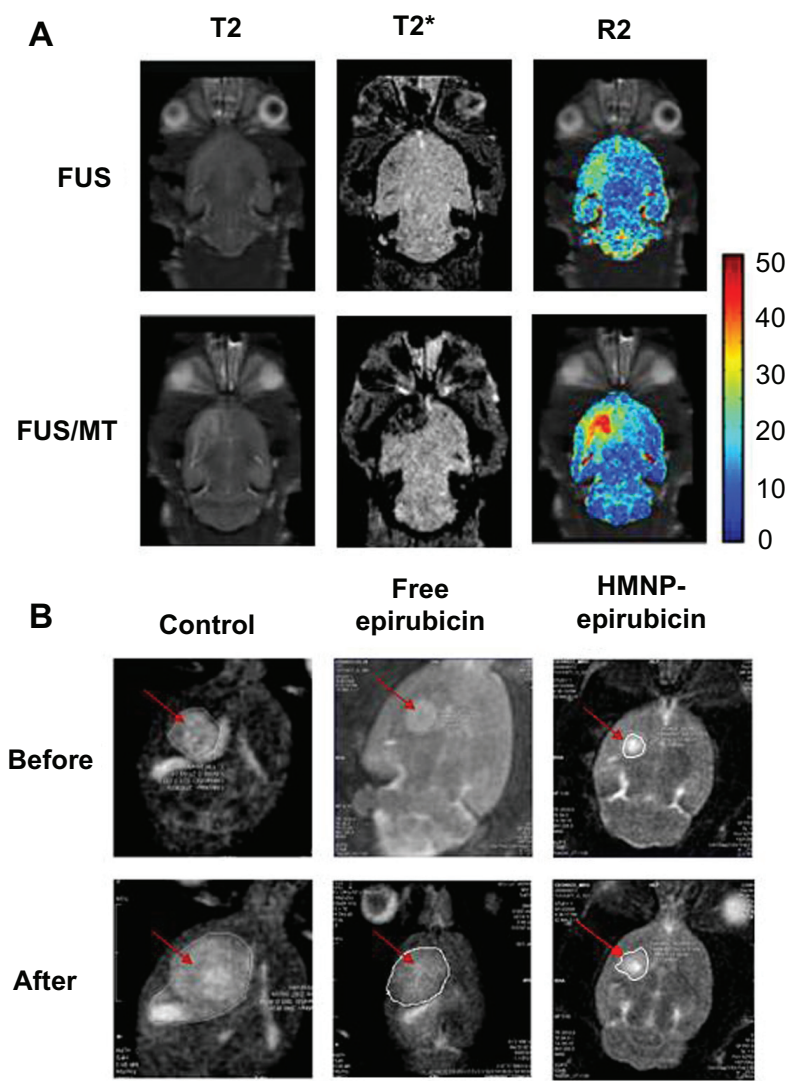

Figure 4 (A) In vivo imaging of high-magnetization magnetic nanoparticle (HMNP) distribution in the brain. Focused ultrasound sonication after HMNPs injection (top) and focused ultrasound followed by magnetic targeting after HMNPs injection (bottom) (left, T2-weighted images; middle, T2*-weighted images; right, combined R2 maps and T2-weighted images). (B) Magnetic resonance images of rat brains with tumors induced by intracranial injection of $\mathrm{C} 6$ cells (arrows). Animals were treated with intravenous free epirubicin (middle) or HMNP-epirubicin and application of focused ultrasound/magnetic targeting.

Note: Images were taken on the day of treatment (day zero: before) and I week later (day seven: after).

Abbreviations: FUS, focused ultrasound; HMNP, high-magnetization magnetic nanoparticle; MT, magnetic targeting. treatment (30.5 days versus 18.3 days, respectively).$^{78}$ FUS combined with magnetic targeting to both passively and actively deliver HMNPs thus represents a powerful technique to enhance the delivery of a wide range of macromolecular therapeutic substances into the central nervous system under the guidance and in vivo monitoring of drug quantification/ distribution by MRI.

The synergistic drug delivery approach also provided an improvement of approximately 3.4-fold in the drug's half-life (from 18 hours to 62 hours). Because of the longer circulation time of EPEG-MNP-BCNU, its accumulation was excellent (177.33 $\pm 23.13 \mu \mathrm{g}$ of iron ion) and approximately 1.65 -fold higher than that of HMNP-BCNU $(107.72 \pm 29.72 \mu \mathrm{g}$ of iron ion) after 24 hours of magnetic targeting. This observation supports the idea that EPEG-HMNP-BCNU is more suitable than HMNP-BCNU for in vivo antitumor studies. The survival rate in animals that received a low dose of BCNU (4.5 mg BCNU/kg) in the form of EPEG-HMNP-BCNU was 63 days compared with 50 days in animals that received a high dose of free BCNU (13.5 mg BCNU/kg). ${ }^{39}$ This improvement could greatly enhance the potential of magnetic targeting therapy in clinical applications of cancer treatments.

\section{Dual-targeted drug delivery in prostate cancer}

Prostate cancer is a slow-growing, potentially lethal disease. It is the sixth most common cancer in the world, in terms of the number of new cases, the third most common cancer in men, and the most common cancer in men in Europe, North America, and some parts of Africa. ${ }^{80,81}$ For advanced prostate cancer, endocrine therapy by androgen ablation is still the mainstay of treatment. However, in most advanced cases of prostate cancer, cells become hormone refractory and the patient eventually dies as the disease progresses. Chemotherapy with taxane drugs such as paclitaxel and docetaxel is currently the standard treatment; docetaxel prolongs the progression-free period and overall survivability of patients. ${ }^{82}$ However, patients can suffer from chemotherapeutic, and especially hematologic, toxicity. In cases of uncontrollable toxicity, the standard dose must be modified; in extreme cases, the patient might even need to be withdrawn from the treatment. One promising candidate for targeted prostate cancer therapy is prostate-specific membrane antigen (PSMA), a 100-kDa type II glycosylated transmembrane protein that is specifically overexpressed on the surface of human prostate cancer cell lines (LNCaP and CWR22R). Although there have been several reports of targeting nanomedicine to tumor cells using specific biomolecules, ${ }^{83-85}$ the delivery efficiency has generally been low because of 
insufficient target-binding ability or activation of the drug, and short circulation times in the blood. Yang et al suggested that another force such as external magnetic guidance must be applied to assist molecular targeting and to amplify the homing of anticancer drugs to tumors. ${ }^{41}$ However, several factors have limited their application, including insufficient stability in aqueous media and marked reticuloendothelial uptake. The circulation time of MNPs in blood is only on the order of minutes due to their rapid capture and clearance by macrophages, especially in the liver. ${ }^{86,87}$

A long circulation time in the bloodstream is a key requirement for specific targeting of nanomedicine and in vivo drug delivery. Yang et al modified paclitaxel-HMNP with functional amino-EPEG-carboxylic acid to prolong its circulation in the blood. ${ }^{41}$ The amount of iron remaining in systemic circulation 6 minutes after drug administration was $81 \%$ for paclitaxel-HMNP-EPEG and 12\% for paclitaxelHMNP. The blood half-life of paclitaxel-HMNP-EPEG was significantly prolonged to 26.8 minutes compared to 2.9 minutes for paclitaxel-HMNP. All forms of the drug were toxic toward CWR22R cells in a dose-dependent manner (Figure $3 \mathrm{C}$ ). The $\mathrm{IC}_{50}$ of free paclitaxel was $9.6 \mu \mathrm{g} / \mathrm{mL}$, which was higher than that of paclitaxel-HMNP-EPEG and paclitaxel-HMNP-EPEG-anti-PSMA (both $5.9 \mu \mathrm{g} / \mathrm{mL}$ ). The $\mathrm{IC}_{50}$ of paclitaxel-HMNP-EPEG-anti-PSMA was significantly further reduced to $2.2 \mu \mathrm{g} / \mathrm{mL}$ when a 900 -gauss magnetic field was applied, presumably because more of it was guided to the cells, further enhancing the local drug concentration.

The efficacy of in vivo local delivery of paclitaxel bioconjugates into subcutaneous tumors by molecular and magnetic targeting was also investigated. T2-weighted MRI was used to evaluate the susceptibility to artifact-induced signal loss caused by HMNP accumulation, and R2 maps were used to detect changes caused by different amounts of HMNPs. It was found that a small amount of paclitaxel-HMNPEPEG accumulated due to the enhanced permeability and retention effect. Accumulation was slightly increased by the multivalent effect of anti-PSMA binding to PSMA on the cell membrane. However, accumulation of paclitaxelHMNP-EPEG-anti-PSMA was significantly increased by approximately 10.3-fold at the tumor site after a 12-hour exposure to magnetic targeting compared to no magnetic targeting treatment. Inductively coupled plasma optical emission spectrometry confirmed the results of the MRI R2 maps. The concentration of accumulated iron was $178.1 \mu \mathrm{g} / \mathrm{mouse}$ after 12 hours of magnetic targeting coupled with injection of paclitaxel-HMNP-EPEG-anti-PSMA, which was higher than injections of paclitaxel-HMNP-EPEG with magnetic targeting (132.6 $\mu \mathrm{g} / \mathrm{mouse})$ and paclitaxel-HMNP-EPEGanti-PSMA alone (19.8 $\mu \mathrm{g} /$ mouse). R2 maps can therefore serve as a good tool not only for quantification but also for imaging the local distribution of magnetic nanomedicines in vivo. The increased accumulation occurred because paclitaxel-HMNP-EPEG-anti-PSMA was bound to the cell surface by multivalent forces during the magnetic targeting period, indicating that a combination of molecular and magnetic targeting could maximize the accumulation of chemotherapeutic drugs.

Treatment efficacy using free and bioconjugated paclitaxel was also evaluated in mice with hypodermic tumors induced by the injection of CWR22R cells (Figure 5A-D). The combination of paclitaxel-HMNP-EPEG-anti-PSMA and 12 hours of magnetic targeting was most effective for controlling tumor progression. Approximately $34.7 \%(51.6 \pm 5.7 \mu \mathrm{g})$ of the initial dose ( $148.5 \mu \mathrm{g} /$ mouse $)$ of paclitaxel was concentrated at the tumor, which was 26.7-fold higher than for the free paclitaxel injection (1.3\% initial dose). Over a 28 -day period, the tumor volume increased by $202 \% \pm 153 \%$ in the paclitaxel-HMNP-EPEG-anti-PSMA/magnetic targeting group (effective paclitaxel dose of $4.5 \mathrm{mg} / \mathrm{kg}$ ) and by $888 \% \pm 234 \%$ in the paclitaxel-HMNP-EPEG/magnetic targeting group (effective paclitaxel dose of $4.5 \mathrm{mg} / \mathrm{kg}$ ) compared to $2873 \% \pm 495 \%$ in the untreated control group and $2568 \% \pm 624 \%$ for treatment with free paclitaxel $(6.0 \mathrm{mg} / \mathrm{kg})$. Tumor growth was slightly inhibited $(1952 \% \pm 382 \%)$ in the paclitaxel-HMNP-EPEG-anti-PSMA treated group without magnetic targeting (Figure 5E), indicating that molecular targeting increased binding affinity but was not sufficient to overcome the effects of blood flow and uptake by macrophages. In contrast, magnetic targeting played an important role in enhancing the accumulation of paclitaxel bioconjugates at the tumor site. Although treatment with free paclitaxel or paclitaxel-HMNP-EPEG-anti-PSMA alone increased median animal survival from 25 days to 35 days and 39 days, respectively, the survival showed a significant further increase in animals receiving 12 hours of magnetic targeting treatment together with paclitaxel-HMNP-EPEG or paclitaxel-HMNP-EPEG-anti-PSMA (median survival: 51 days and 65 days, respectively; Figure 5F). Blood biochemistry analyses confirmed that neither liver nor renal functions were affected, even at 14 days after injection of the highest dose of HMNP-EPEG (30 mg/kg). This system was found to be efficient, nontoxic, and specific for the administration 

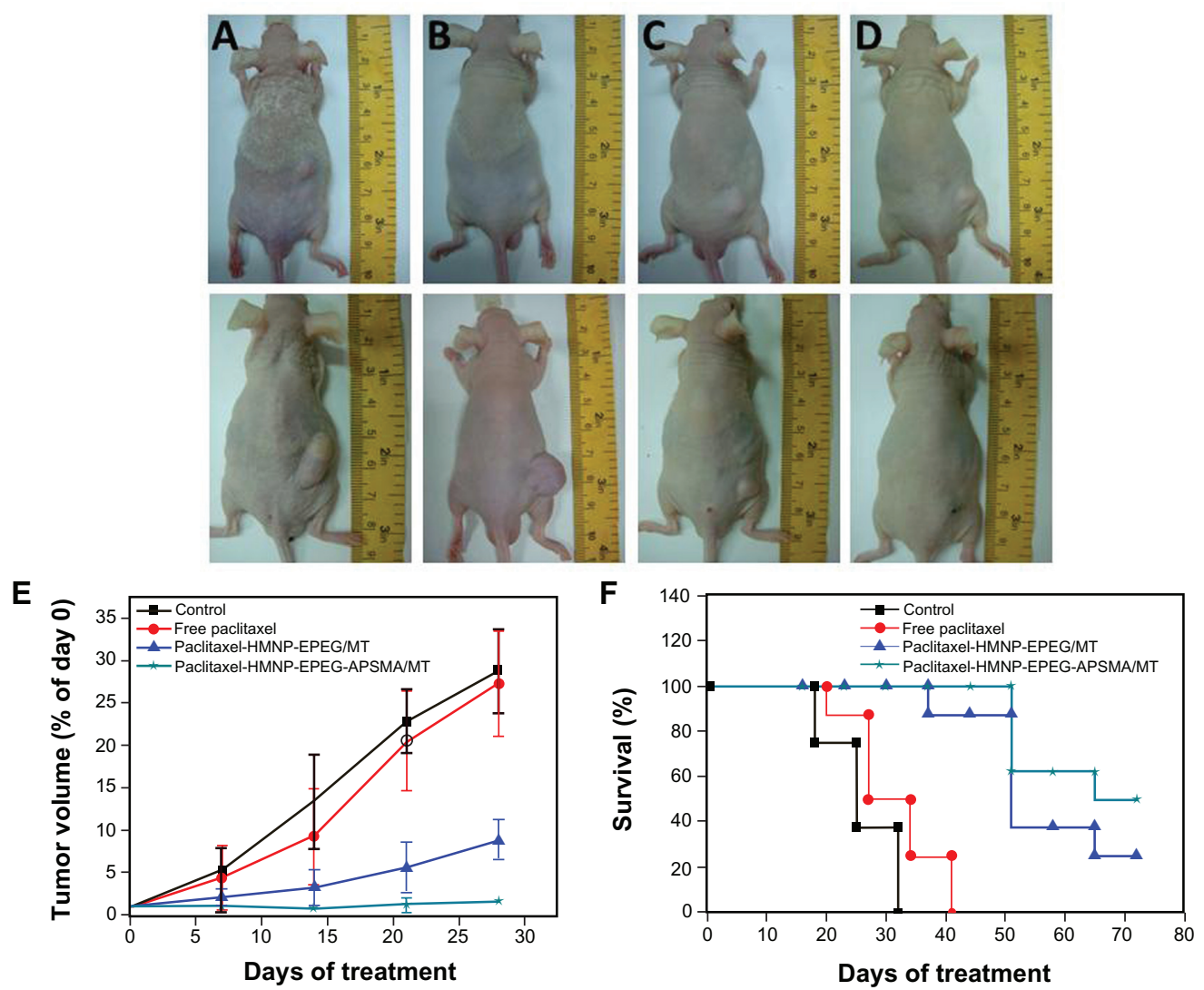

Figure 5 Images of representative mice at the beginning (top) and the endpoint (28 days after treatment, bottom) for (A) control, (B) free paclitaxel, (C) paclitaxelhigh-magnetization magnetic nanoparticle-O-(2-aminoethyl)polyethylene glycol/magnetic targeting, and (D) paclitaxel-high-magnetization magnetic nanoparticleO-(2-aminoethyl)polyethylene glycol-antiprotein-specific membrane antigen/magnetic targeting. (E) Quantitative analysis of the effects of various treatments on tumor size. (F) Survival plots of animal experiments.

Notes: Values represent mean \pm standard deviation $(n=8)$; animals were euthanized when the implanted tumor volume reached $3 \mathrm{~cm}^{3}$.

Abbreviations: APSMA, antiprotein-specific membrane antigen; EPEG, O-(2-aminoethyl)polyethylene glycol; HMNP, high-magnetization magnetic nanoparticle; MT, magnetic targeting.

of HMNP-based chemotherapy with significant potential for treating human prostatic carcinoma in vivo.

\section{Site specific drug delivery and overcoming multidrug resistance (MDR) in bladder tumors}

A little more than half of cancer patients are cured by current cancer therapies. Surgery is considered the most efficient treatment for small tumors which are rarely accompanied by metastasis. Chemotherapy is the key treatment after surgery, despite serious side effects, especially for large and spreading tumors. A major clinical barrier to the efficacy of chemotherapeutic agents is the resistance of cancer cells, known as MDR. Up to $75 \%$ of chemotherapy patients express markers of MDR; it almost invariably emerges and introduces a major obstacle to curative therapy of human malignancies. ${ }^{88}$ MDR can arise through various mechanisms that are not fully understood. The most recognized mechanisms include:
(1) decreased drug uptake or increased drug efflux, such as mediated by P-glycoprotein; ${ }^{89}$ (2) altered drug activation or degradation; ${ }^{90}$ (3) enhanced DNA repair; $;{ }^{91}$ and (4) failure of drug activity to trigger enzyme-induced apoptosis. ${ }^{92}$ Despite two decades of research efforts devoted to reversing cancer MDR, no clinically promising method has emerged ${ }^{93}$ Nuclear drug resistance (NDR) mediated by the nuclear membrane export effect currently plays a major role in the failure of treating MDR cells.

Yang et al developed epirubicin or doxorubicin conjugates based on HMNPs to overcome MDR, including NDR. ${ }^{40}$ The distribution of epirubicin in MGH-U1 (bladder carcinoma cell line) and MGH-U1R cells (NDR bladder carcinoma cell line) can be visualized by confocal microscopy with excitation at $488 \mathrm{~nm}$. Free epirubicin and HMNP-epirubicin both entered MGH-U1 cells and even nuclei, but HMNP-epirubicin appeared to be taken up by an endocytotic pathway, ${ }^{94}$ thus avoiding the effects of P-glycoprotein pumps and enhancing 

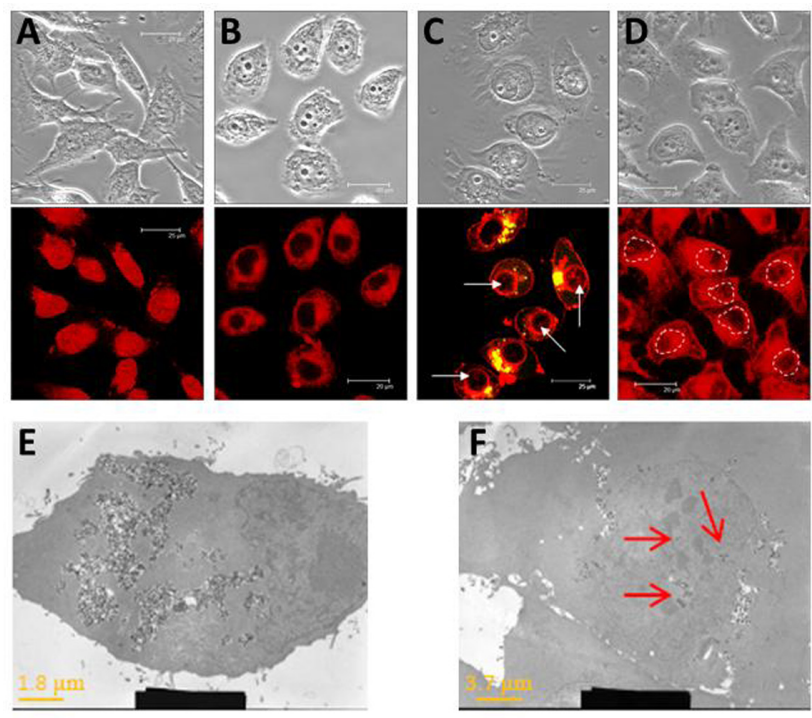

Figure 6 Fluorescence and phase contrast images of (A) MGH-UI cells; (B) MGH-UIR cells exposed to $6 \mu \mathrm{g} / \mathrm{mL}$ of free epirubicin; (C) MGH-UIR cells exposed to $6 \mu \mathrm{g} / \mathrm{mL}$ of free epirubicin with pretreatment of $0.5 \mathrm{mg} / \mathrm{mL}$ wheat germ agglutinin for 24 hours; and (D) MGH-UIR cells exposed to high-magnetization magnetic nanoparticle-epirubicin with effective epirubicin concentration of $6 \mu \mathrm{g} / \mathrm{mL}$. Transmission electron microscope images of (E) MGH-UI cells and (F) MGH-UIR cells exposed to high-magnetization magnetic nanoparticle-epirubicin.

Note: Arrows denote high-magnetization magnetic nanoparticle-epirubicin.

its intracellular concentration by $27.3 \% \pm 4.2 \%(n=50)$ relative to free epirubicin. After 8 hours of incubation, HMNPepirubicin was still detectable in the nuclei and was dispersed evenly within the cytoplasm, possibly because of its release from lysosomes and endosomes. MGH-U1R cells usually resist the presence of epirubicin in nuclei, limiting treatment.
Wheat germ agglutinin, which is known to inhibit nuclear transport, can be used to inhibit export from the nucleus to the cytoplasm, resulting in a low concentration of epirubicin remaining in the nuclei. Strikingly, HMNP-epirubicin was capable of passing through the nuclear membrane and stayed in the nuclei even in the absence of pretreatment with wheat germ agglutinin, indicating a reversal of the NDR effect (Figure 6A-D). Transmission electron microscope images confirmed that large quantities of HMNP-epirubicin passed through cell membranes of MGH-U1 cells via an endocytotic pathway, entered the nuclei by binding to importin (or proteasomes), and then remained in the nuclei of MGH-U1R cells (Figure 6E and F).

In contrast to HMNPs, free epirubicin and HMNPepirubicin were both toxic to MGH-U1 cells in a dose-dependent manner. The $\mathrm{IC}_{50}$ of HMNP-epirubicin was $3.1 \mu \mathrm{g} / \mathrm{mL}$, which was lower than that of free epirubicin $(3.7 \mu \mathrm{g} / \mathrm{mL})$ due to the elimination of the P-glycoprotein pump effect and better stability. The $\mathrm{IC}_{50}$ value of HMNP-epirubicin was significantly further reduced to only $1.9 \mu \mathrm{g} / \mathrm{mL}$ when applying magnetic targeting. Thus, magnetic targeting has the potential to significantly improve the therapeutic concentration and reduce the total amount of drug required. In the case of NDR, free epirubicin failed to inhibit the growth of MGH-U1R cells at concentrations $\leq 14.5 \mu \mathrm{g} / \mathrm{mL}$. The $\mathrm{IC}_{50}$ value of HMNP-epirubicin was $10.1 \mu \mathrm{g} / \mathrm{mL}$ lower than that of free epirubicin $(12.2 \mu \mathrm{g} / \mathrm{mL})$ in cells pretreated with $0.5 \mathrm{mg} /$ $\mathrm{mL}$ wheat germ agglutinin. This value was significantly
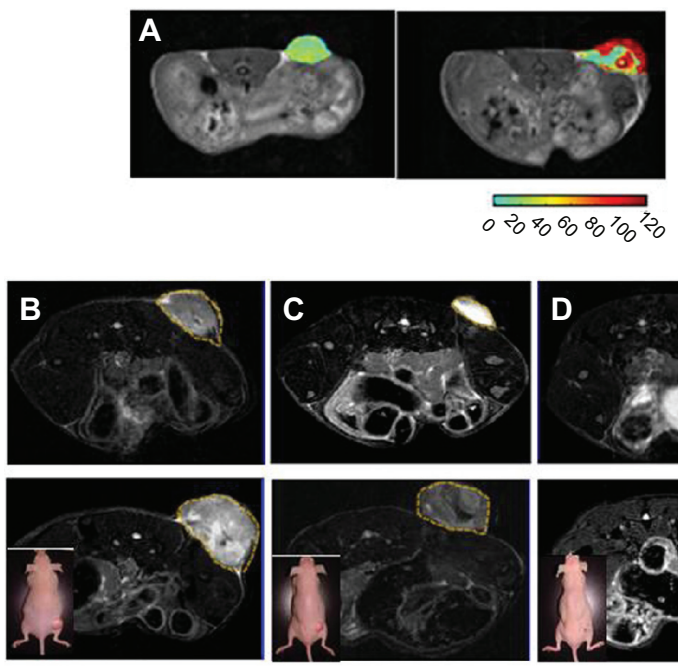
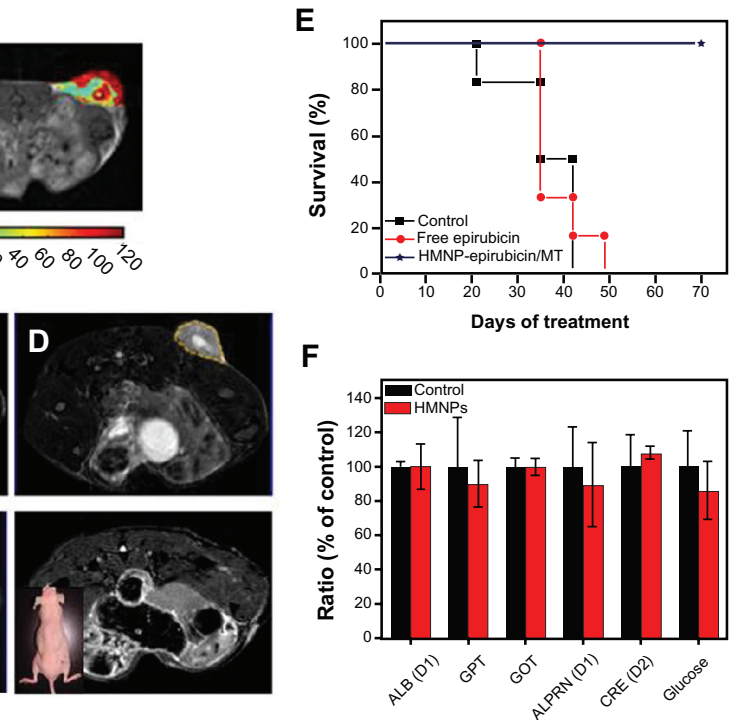

Figure 7 (A) In vivo imaging of high-magnetization magnetic nanoparticle-epirubicin distribution in hypodermic tumors before (left) and after magnetic targeting (right, $0.4 \mathrm{~T}$ ). In vivo T2-weighted images of representative mice at the beginning (top) and the endpoint (28 days after treatment, bottom) for (B) control, (C) free epirubicin, (D) high-magnetization magnetic nanoparticle-epirubicin/magnetic targeting. (E) Survival plots of the animal experiments. (F) Blood biochemistry analysis at 21 days after injection of high-magnetization magnetic nanoparticles.

Abbreviations: HMNP, high-magnetization magnetic nanoparticle; MT, magnetic targeting. 
further reduced to $6.7 \mu \mathrm{g} / \mathrm{mL}$ when magnetic targeting was combined with HMNP-epirubicin (Figure 3D).

The efficacy of free epirubicin or MNP-epirubicin treatment was further evaluated in mice with hypodermic tumors introduced by injection of MGH-U1R cells. Treatment with free epirubicin failed to show significant growth inhibition of NDR tumors compared to controls. Impressively, treatment with MNP-epirubicin combined with magnetic targeting therapy for 36 hours provided an effective means of controlling tumor progression, concentrating about $25.7 \%$ (45.6 $\mu \mathrm{g} / \mathrm{mouse})$ of the initial injected dose of epirubicin (177.2 $\mu \mathrm{g} / \mathrm{mouse}$ ) in the tumor (Figure 7A). Over a 28-day period, the tumor was completely eliminated in treated mice (effective epirubicin of $5.8 \mathrm{mg} / \mathrm{kg}$ by magnetic targeting of MNP-epirubicin) by just two injections (one every week), compared with a $441.7 \% \pm 39.9 \%$ tumor increase in untreated controls and a $420.7 \% \pm 54.1 \%$ tumor increase for free epirubicin $(17.4 \mu \mathrm{g} / \mathrm{kg}$ ) (Figure 7B-D). Survival was significantly prolonged ( $>70$ days) in animals receiving MNP-epirubicin with 36 hours of magnetic targeting treatment, compared to shorter survival in other groups (median survival: 35-42 days; Figure 7E). Blood biochemistry analyses confirmed that neither liver nor renal functions were affected even 21 days after injection of the highest dose of HMNPs (Figure 7F). Thus magnetic drug delivery not only exploits the advantages of magnetic targeting but also significantly reverses NDR to inhibit tumor growth at lower doses and reduce serious side effects (ie, cardiotoxicity) of chemotherapeutic drugs.

\section{Conclusion and future directions}

Although recent advances have demonstrated the feasibility of using targeted MNPs for tumor imaging and therapy, new methods and strategies are needed to further develop tumor-targeted imaging probes. Future MNPs need to have high specificity and sensitivity, have prolonged circulation in blood, and eventually be metabolized. Here, the broad potential of MNPs for drug delivery, cancer therapy, diagnosis and imaging, and separation were reviewed. However, some of these strategies will need to be combined to maximize efficacy and allow the widespread use of MNPs to treat any carcinoma. For example, for brain tumors, FUS - to locally enhance blood-brain barrier disruption and delivery of therapeutic MNPs - can be integrated with a novel magnetic targeting approach so that drug delivery proceeds through both passive and active diffusion. Magnets need to be placed externally to provide magnetic targeting after FUS exposure, and they significantly enhance the active attraction of thera- peutic MNP by at least an order of concentration. In other kinds of tumors, therapeutic MNPs could be combined with a specific biomarker, ligand, or antibody to produce dualtargeted nanomedicine and further optimize MNP-mediated cancer treatment. In addition, chemotherapeutic MNPs can be delivered intravenously rather than intraarterially or by direct tumor injection, which makes the treatment more practical in a clinical setting.

Despite their tremendous promise, further translation of MNPs to clinical applications will require several outstanding issues to be addressed in a comprehensive manner as part of preclinical and clinical studies. The long-term effects of MNPs need to be investigated in detail. Concerns associated with long-term tissue damage, toxicity, carcinogenesis, immunogenicity, and inflammation need to be addressed to optimize the structure and design of MNPs.

MNPs have demonstrated tremendous promise as theranostics for the detection and treatment of cancer. MNPs should be further investigated and smart MNPs need to be explored with the aim of creating successful nanobiotechnology in biochemical and biomedical applications.

\section{Acknowledgments}

The authors thank the National Science Council of the Republic of China, Chang Gung Memorial Hospital, and the National Health Research Institute for financial support (NSC 100-2221-E-182-005, NSC 100-2120-M-182A-001, CMRPD140041, CMRPG3A0031, CMRPG3A0501, CMRPG3A0531, NHRI-EX100-10004NI). The authors also thank the Molecular Imaging Center, Chang Gung Memorial Hospital (Taoyuan, Taiwan) for supporting MRI of the animals in this study.

\section{Disclosure}

The authors report no conflicts of interest in this work.

\section{References}

1. Maeda H, Wu J, Sawa T, Matsumura Y, Hori K. Tumor vascular permeability and the EPR effect in macromolecular therapeutics: a review. J Control Release. 2000;65(1-2):271-284.

2. Poizot P, Laruelle S, Grugeon S, Dupont L, Tarascon JM. Nano-sized transition-metal oxides as negative-electrode materials for lithium-ion batteries. Nature. 2000;407(6803):496-499.

3. Tari A, Chantrell RW, Charles SW, Popplewell J. The magnetic properties and stability of a ferrofluid containing $\mathrm{Fe}_{3} \mathrm{O}_{4}$ particles. Physica $B$ and C. 1979;97(1):57-64.

4. Mahmoudi M, Simchi A, Imani M, Stroeve P, Sohrabi A. Templated growth of superparamagnetic iron oxide nanoparticles by temperature programming in the presence of poly(vinyl alcohol). Thin Solid Films. 2010;518(15):4281-4289.

5. Jaffer FA, Weissleder R. Molecular imaging in the clinical arena. JAMA 2005;293(7):855-862. 
6. Perez JM, Simeone FJ, Saeki Y, Josephson L, Weissleder R. Viral-induced self-assembly of magnetic nanoparticles allows the detection of viral particles in biological media. J Am Chem Soc. 2003;125(34): 10192-10193.

7. Lewin M, Carlesso N, Tung CH, et al. Tat peptide-derivatized magnetic nanoparticles allow in vivo tracking and recovery of progenitor cells. Nat Biotechnol. 2000;18(4):410-414.

8. Hong J, Xu J, Gong P, Yu J, Ma H, Yao S. Covalent-bonded immobilization of enzyme on hydrophilic polymer covering magnetic nanogels. Microporous Mesoporous Mater. 2008;109(1-3):470-477.

9. Hood JD, Bednarski M, Frausto R, et al. Tumor regression by targeted gene delivery to the neovasculature. Science. 2002;296(5577): 2404-2407.

10. Hua MY, Yang HW, Liu HL, et al. Superhigh-magnetization nanocarrier as a doxorubicin delivery platform for magnetic targeting therapy. Biomaterials. 2011;32(34):8999-9010.

11. Hafeli UO, Sweeney SM, Beresford BA, Humm JL, Macklis RM. Effective targeting of magnetic radioactive $90 \mathrm{Y}$-microspheres to tumor cells by an externally applied magnetic field. Preliminary in vitro and in vivo results. Nucl Med Biol. 1995;22(2):147-155.

12. Ying XY, Du YZ, Hong LH, Yuan H, Hu FQ. Magnetic lipid nanoparticles loading doxorubicin for intracellular delivery: preparation and characteristics. J Magn Magn Mater. 2011;323(8):1088-1093.

13. Nitin N, LaConte LE, Zurkiya O, Hu X, Bao G. Functionalization and peptide-based delivery of magnetic nanoparticles as an intracellular MRI contrast agent. J Biol Inorg Chem. 2004;9(6):706-712.

14. Bogdanov AA Jr, Martin C, Weissleder R, Brady TJ. Trapping of dextran-coated colloids in liposomes by transient binding to aminophospholipid: preparation of ferrosomes. Biochim Biophys Acta. 1994; 1193(1):212-218

15. Bulte JW, De Cuyper M. Magnetoliposomes as contrast agents. Methods Enzymol. 2003;373:175-198.

16. Bulte JW, Douglas T, Mann S, et al. Magnetoferritin: characterization of a novel superparamagnetic MR contrast agent. J Magn Reson Imaging. 1994;4(3):497-505.

17. Wilhelm C, Billotey C, Roger J, Pons JN, Bacri JC, Gazeau F. Intracellular uptake of anionic superparamagnetic nanoparticles as a function of their surface coating. Biomaterials. 2003;24(6):1001-1011.

18. Jiang W, Sun Z, Li F, et al. A novel approach to preparing magnetic protein microspheres with core-shell structure. J Magn Magn Mater. 2011;323(5):435-439.

19. Lin JJ, Chen JS, Huang SJ, et al. Folic acid-Pluronic F127 magnetic nanoparticle clusters for combined targeting, diagnosis, and therapy applications. Biomaterials. 2009;30(28):5114-5124.

20. Veiseh O, Kievit FM, Fang C, et al. Chlorotoxin bound magnetic nanovector tailored for cancer cell targeting, imaging, and siRNA delivery. Biomaterials. 2010;31(31):8032-8042.

21. Chen PY, Liu HL, Hua MY, et al. Novel magnetic/ultrasound focusing system enhances nanoparticle drug delivery for glioma treatment. Neuro Oncol. 2010;12(10):1050-1060.

22. Cole AJ, David AE, Wang J, Galban CJ, Hill HL, Yang VC. Polyethylene glycol modified, cross-linked starch-coated iron oxide nanoparticles for enhanced magnetic tumor targeting. Biomaterials. 2011;32(8):2183-2193.

23. Bi F, Zhang J, Su Y, Tang YC, Liu JN. Chemical conjugation of urokinase to magnetic nanoparticles for targeted thrombolysis. Biomaterials. 2009;30(28):5125-5130.

24. Rogers WJ, Basu P. Factors regulating macrophage endocytosis of nanoparticles: implications for targeted magnetic resonance plaque imaging. Atherosclerosis. 2005;178(1):67-73.

25. Bradbury M, Hricak H. Molecular MR imaging in oncology. Magn Reson Imaging Clin N Am. 2005;13(2):225-240.

26. Montet X, Montet-Abou K, Reynolds F, Weissleder R, Josephson L. Nanoparticle imaging of integrins on tumor cells. Neoplasia. 2006;8(3):214-222.

27. Shen T, Weissleder R, Papisov M, Bogdanov A Jr, Brady TJ. Monocrystalline iron oxide nanocompounds (MION): physicochemical properties. Magn Reson Med. 1993;29(5):599-604.
28. Wang YX, Hussain SM, Krestin GP. Superparamagnetic iron oxide contrast agents: physicochemical characteristics and applications in MR imaging. Eur Radiol. 2001;11(11):2319-2331.

29. Thorek DL, Chen AK, Czupryna J, Tsourkas A. Superparamagnetic iron oxide nanoparticle probes for molecular imaging. Ann Biomed Eng. 2006;34(1):23-38.

30. Lee H, Lee E, Kim do K, Jang NK, Jeong YY, Jon S. Antibiofouling polymer-coated superparamagnetic iron oxide nanoparticles as potential magnetic resonance contrast agents for in vivo cancer imaging. $J \mathrm{Am}$ Chem Soc. 2006;128(22):7383-7389.

31. Lacava LM, Lacava ZG, Da Silva MF, et al. Magnetic resonance of a dextran-coated magnetic fluid intravenously administered in mice. Biophys J. 2001;80(5):2483-2486.

32. Davis SS. Biomedical applications of nanotechnology - implications for drug targeting and gene therapy. Trends Biotechnol. 1997;15(6): 217-224.

33. Gaur U, Sahoo SK, De TK, Ghosh PC, Maitra A, Ghosh PK. Biodistribution of fluoresceinated dextran using novel nanoparticles evading reticuloendothelial system. Int J Pharm. 2000;202(1-2):1-10.

34. Jeong YI, Seo SJ, Park IK, et al. Cellular recognition of paclitaxel-loaded polymeric nanoparticles composed of poly $(\gamma$-benzyl L-glutamate) and poly(ethylene glycol) diblock copolymer endcapped with galactose moiety. Int J Pharm. 2005;296(1-2):151-161.

35. Kumar A, Sahoo B, Montpetit A, Behera S, Lockey RF, Mohapatra SS. Development of hyaluronic acid- $\mathrm{Fe}_{2} \mathrm{O}_{3}$ hybrid magnetic nanoparticles for targeted delivery of peptides. Nanomedicine. 2007;3(2):132-137.

36. Shi X, Thomas TP, Myc LA, Kotlyar A, Baker JR Jr. Synthesis, characterization, and intracellular uptake of carboxyl-terminated poly(amidoamine) dendrimer-stabilized iron oxide nanoparticles. Phys Chem Chem Phys. 2007;9(42):5712-5720.

37. Hua MY, Yang HW, Chuang CK, et al. Magnetic-nanoparticle-modified paclitaxel for targeted therapy for prostate cancer. Biomaterials. 2010; 31(28):7355-7363.

38. Hua MY, Liu HL, Yang HW, et al. The effectiveness of a magnetic nanoparticle-based delivery system for BCNU in the treatment of gliomas. Biomaterials. 2011;32(2):516-527.

39. Yang HW, Hua MY, Liu HL, et al. Self-protecting core-shell magnetic nanoparticles for targeted, traceable, long half-life delivery of BCNU to gliomas. Biomaterials. 2011;32(27):6523-6532.

40. Yang HW, Hua MY, Liu HL, et al. An epirubicin-conjugated nanocarrier with MRI function to overcome lethal multidrug-resistant bladder cancer. Biomaterials. 2012;33(15):3919-3930.

41. Yang HW, Hua MY, Liu HL, et al. Cooperative dual-activity targeted nanomedicine for specific and effective prostate cancer therapy. ACS Nano. 2012;6(2):1795-1805.

42. Dames P, Gleich B, Flemmer A, et al. Targeted delivery of magnetic aerosol droplets to the lung. Nat Nanotechnol. 2007;2(8):495-499.

43. Dini L, Abbro L. Bioeffects of moderate-intensity static magnetic fields on cell cultures. Micron. 2005;36(3):195-217.

44. Arias JL, Gallardo V, Gomez-Lopera SA, Plaza RC, Delgado AV. Synthesis and characterization of poly(ethyl-2-cyanoacrylate) nanoparticles with a magnetic core. J Control Release. 2001;77(3):309-321.

45. Hu FX, Neoh KG, Kang ET. Synthesis and in vitro anti-cancer evaluation of tamoxifen-loaded magnetite/PLLA composite nanoparticles. Biomaterials. 2006;27(33):5725-5733.

46. Ikeda N, Hayashida O, Kameda H, Ito H, Matsuda T. Experimental study on thermal damage to dog normal brain. Int $J$ Hyperthermia. 1994;10(4):553-561.

47. Goldstein LS, Dewhirst MW, Repacholi M, Kheifets L. Summary, conclusions and recommendations: adverse temperature levels in the human body. Int J Hyperthermia. 2003;19(3):373-384.

48. Matsuoka F, Shinkai M, Honda H, Kubo T, Sugita T, Kobayashi T. Hyperthermia using magnetite cationic liposomes for hamster osteosarcoma. Biomagn Res Technol. 2004;2(1):3.

49. Du Y, Zhang D, Liu H, Lai R. Thermochemotherapy effect of nanosized $\mathrm{As}_{2} \mathrm{O}_{3} / \mathrm{Fe}_{3} \mathrm{O}_{4}$ complex on experimental mouse tumors and its influence on the expression of CD44v6, VEGF-C and MMP-9. BMC Biotechnol. 2009;9:84. 
50. Jang JT, Nah H, Lee JH, Moon SH, Kim MG, Cheon J. Critical enhancements of MRI contrast and hyperthermic effects by dopant-controlled magnetic nanoparticles. Angew Chem Int Ed Engl. 2009;48(7): 1234-1238.

51. Saiyed ZM, Telang SD, Racnchand CN. Application of magnetic techniques in the field of drug discovery and biomedicine. Biomagn Res Technol. 2003;1(1):23-33.

52. Schneider S, Rusconi S. Magnetic selection of transiently transfected cells. Biotechniques. 1996;21(5):876-880.

53. Spanova A, Rittich B, Horak D, et al. Immunomagnetic separation and detection of Salmonella cells using newly designed carriers J Chromatogr A. 2003;1009(1-2):215-221.

54. Bornscheuer UT. Immobilizing enzymes: how to create more suitable biocatalysts. Angew Chem Int Ed Engl. 2003;42(29): 3336-3337.

55. Liao MH, Chen DH. Immobilization of yeast alcohol dehydrogenase on magnetic nanoparticles for improving its stability. Biotechnol Lett 2001;23(20):1723-1727.

56. Huang SH, Liao MH, Chen DH. Direct binding and characterization of lipase onto magnetic nanoparticles. Biotechnol Prog. 2003;19(3): 1095-1100.

57. Libertino S, Scandurra A, Aiello V, et al. Layer uniformity in glucose oxidase immobilization on $\mathrm{SiO}_{2}$ surfaces. Appl Surf Sci. 2007;253(23): 9116-9123.

58. Park HJ, McConnell JT, Boddohi S, Kipper MJ, Johnson PA. Synthesis and characterization of enzyme-magnetic nanoparticle complexes effect of size on activity and recovery. Colloid Surf B Biointerfaces 2011;83(2):198-203.

59. Dyal A, Loos K, Noto M, et al. Activity of Candida rugosa lipase immobilized on $\gamma-\mathrm{Fe}_{2} \mathrm{O}_{3}$ magnetic nanoparticles. J Am Chem Soc. 2003 125(7):1684-1685.

60. Huang J, Zhao R, Wang H, Zhao W, Ding L. Immobilization of glucose oxidase on $\mathrm{Fe}_{3} \mathrm{O}_{4} / \mathrm{SiO}_{2}$ magnetic nanoparticles. Biotechnol Lett. 2010; 32(6):817-821.

61. Akutsu J, Tojo Y, Segawa O, et al. Development of an integrated automation system with a magnetic bead-mediated nucleic acid purification device for genetic analysis and gene manipulation. Biotechnol Bioeng. 2004;86(6):667-671.

62. Georgieva J, Milling A, Orfanos CE, Geilen CC. Magnetic bead RT-PCR: establishment of a new method for detecting circulating melanoma cells. Melanoma Res. 2002;12(4):309-317.

63. Archer MJ, Lin B, Wang Z, Stenger DA. Magnetic bead-based solid phase for selective extraction of genomic DNA. Anal Biochem. 2006; 355(2):285-297.

64. Wang L, Yang Z, Gao J, et al. A biocompatible method of decorporation bisphosphonate-modified magnetite nanoparticles to remove uranyl ions from blood. J Am Chem Soc. 2006;128(41):13358-13359.

65. Herrmann IK, Urner M, Koehler FM, et al. Blood purification using functionalized core/shell nanomagnets. Small. 2010;6(13):1388-1392.

66. Massoud TF, Gambhir SS. Molecular imaging in living subjects: seeing fundamental biological processes in a new light. Genes Dev. 2003;17(5): 545-580.

67. Guimaraes AR, Ross R, Figuereido JL, Waterman P, Weissleder R. MRI with magnetic nanoparticles monitors downstream anti-angiogenic effects of mTOR inhibition. Mol Imaging Biol. 2011;13(2): 314-320.

68. Korosoglou G, Tang L, Kedziorek D, et al. Positive contrast MR-lymphography using inversion recovery with ON-resonant water suppression (IRON). J Magn Reson Imaging. 2008;27(5):1175-1180.

69. Morishige K, Kacher DF, Libby P, et al. High-resolution magnetic resonance imaging enhanced with superparamagnetic nanoparticles measures macrophage burden in atherosclerosis. Circulation. 2010;122(17): 1707-1715.

70. Sosnovik DE, Nahrendorf M, Panizzi P, et al. Molecular MRI detects low levels of cardiomyocyte apoptosis in a transgenic model of chronic heart failure. Circ Cardiovasc Imaging. 2009;2(6):468-475.

71. Shen CR, Wu ST, Tsai ZT, et al. Characterization of quaternized chitosan-stabilized iron oxide nanoparticles as a novel potential magnetic resonance imaging contrast agent for cell tracking. Polym Int. 2011; 60(6):945-950.
72. Scherer F, Anton M, Schillinger U, et al. Magnetofection: enhancing and targeting gene delivery by magnetic force in vitro and in vivo. Gene Ther. 2002;9(2):102-109.

73. Krötz F, de Wit C, Sohn HY, et al. Magnetofection - a highly efficient tool for antisense oligonucleotide delivery in vitro and in vivo. $\mathrm{Mol}$ Ther. 2003;7(5 Pt 1):700-710.

74. Hirao K, Sugita T, Kubo T, et al. Targeted gene delivery to human osteosarcoma cells with magnetic cationic liposomes under a magnetic field. Int J Oncol. 2003;22(5):1065-1071.

75. Zheng X, Lu J, Deng L, Xiongc Y, Chen J. Preparation and characterization of magnetic cationic liposome in gene delivery. Int $J$ Pharm. 2009;366(1-2):211-217.

76. Chertok B, David AE, Huang Y, Yang VC. Glioma selectivity of magnetically targeted nanoparticles: a role of abnormal tumor hydrodynamics. $J$ Control Release. 2007;122(3):315-323.

77. Chertok B, Moffat BA, David AE, et al. Iron oxide nanoparticles as a drug delivery vehicle for MRI monitored magnetic targeting of brain tumors. Biomaterials. 2008;29(4):487-496.

78. Liu HL, Hua MY, Yang HW, et al. Magnetic resonance monitoring of focused ultrasound/magnetic nanoparticle targeting delivery of therapeutic agents to the brain. Proc Natl Acad Sci U S A. 2010;107(34): 15205-15210.

79. Liu HL, Hsu PH, Chu PC, et al. Magnetic resonance imaging enhanced by superparamagnetic iron oxide particles: usefulness for distinguishing between focused ultrasound-induced blood-brain barrier disruption and brain hemorrhage. J Magn Reson Imaging. 2009;29(1):31-38.

80. Quinn M, Babb P. Patterns and trends in prostate cancer incidence, survival, prevalence and mortality. Part I: international comparisons. BJU Int. 2002;90(2):162-173.

81. Quinn M, Babb P. Patterns and trends in prostate cancer incidence, survival, prevalence and mortality. Part II: individual countries. BJU Int. 2002;90(2):174-184.

82. Tannock IF, de Wit R, Berry WR, et al. Docetaxel plus prednisone or mitoxantrone plus prednisone for advanced prostate cancer. $N$ Engl J Med. 2004;351(15):1502-1512.

83. Cai W, Shin DW, Chen K, et al. Peptide-labeled near-infrared quantum dots for imaging tumor vasculature in living subjects. Nano Lett. 2006; 6(4):669-676.

84. Min K, Jo H, Song K, et al. Dual-aptamer-based delivery vehicle of doxorubicin to both PSMA (+) and PSMA (-) prostate cancers. Biomaterials. 2011;32(8):2124-2132.

85. Sanna V, Pintus G, Roggio AM, et al. Targeted biocompatible nanoparticles for the delivery of $(-)$-epigallocatechin 3-gallate to prostate cancer cells. J Med Chem. 2011;54(5):1321-1332.

86. Na HB, Song IC, Hyeon T. Inorganic nanoparticles for MRI contrast agents. Adv Mater. 2009;21(21):2133-2148.

87. Chertok B, David AE, Yang VC. Polyethyleneimine-modified iron oxide nanoparticles for brain tumor drug delivery using magnetic targeting and intra-carotid administration. Biomaterials. 2010;31(24):6317-6324.

88. Shapira A, Livney YD, Broxterman HJ, Assaraf YG. Nanomedicine for targeted cancer therapy: towards the overcoming of drug resistance. Drug Resist Updat. 2011;14(3):150-163.

89. Dietel M. What's new in cytostatic drug resistance and pathology. Pathol Res Pract. 1991;187(7):892-905.

90. Morrow CS, Cowan KH. Glutathione S-transferases and drug resistance. Cancer Cells. 1990;2(1):15-22.

91. Hammond JR, Johnstone RM, Gros P. Enhanced efflux of (3H) vinblastine from Chinese hamster ovary cells transfected with a fulllength complementary DNA clone for the mdr1 gene. Cancer Res. 1989; 49(14):3867-3871.

92. Liu YY, Han TY, Giuliano AE, Cabot MC. Ceramide glycosilation potentiates cellular multidrug resistance. FASEB J. 2001;15(3): 719-730.

93. Desoize B, Jardillier J. Multicellular resistance: a paradigm for clinical resistance? Crit Rev Oncol Hemat. 2000;36(2-3):193-207.

94. Nam HY, Kwon SM, Chung H, et al. Cellular uptake mechanism and intracellular fate of hydrophobically modified glycol chitosan nanoparticles. J Control Release. 2009;135(3):259-267. 


\section{Publish your work in this journal}

Nanotechnology, Science and Applications is an international, peerreviewed, open access journal that focuses on the science of nanotechnology in a wide range of industrial and academic applications. It is characterized by the rapid reporting across all sectors, including engineering, optics, bio-medicine, cosmetics, textiles, resource sustainability and science. Applied research into nano-materials, particles, nanostructures and fabrication, diagnostics and analytics, drug delivery and toxicology constitute the primary direction of the journal. The manuscript management system is completely online and includes a very quick and fair peer-review system, which is all easy to use.

Submit your manuscript here: http://www.dovepress.com/nanotechnology-science-and-applications-journal 